\title{
Representasi dan Interpretasi Kaomoji (Emotikon Bahasa Jepang) Melalui Pendekatan Semiotika Pierce
}

\author{
Ningrum Tresnasari \\ Universitas Widyatama \\ ningrum.tresnasari@widyatama.ac.id
}

\begin{abstract}
ABSTRAK
Semiotik is one of the studies in linguistics that aims to explain how signs or symbols can represent objects, ideas, conditions, situations, feelings, and conditions outside the symbol itself. This study aims to discuss the use of symbols in the form of Japanese emoticons (kaomoji) in explaining things that are not represented because of limitations in tone, voice, and expression when communicating in a non-verbal way. By using Pierce's semiotic theory, this study also looks at how culture becomes the basis of the formation of meaning in a sign or symbol on kaomoji. In other words, kaomoji has a meaning that aims to emphasize expression, reinforce emotions, and a form of positive appreciation. Besides that, the very varied and creative kaomoji illustrates that Japanese people are very expressive and full of enthusiasm.
\end{abstract}

Keywords : Kaomoji, Non Verbal Communication, Symbol dan Meaning

\section{Pendahuluan}

Emotikon (emoticon) merupakan singkatan dari "emotion icon" yang berarti 'ikon emosi' yang terbuat dari berbagai simbol tulisan yang disatukan hingga menyerupai ekspresi wajah. Emotikon dapat dikatakan sebagai bentuk kreatif visual yang menonjol untuk mempresentasikan emosi ke dalam komunikasi berbasis teks. Emotikon berfungsi sebagai bentuk penekanan nada atau arti dalam pembuatan atau penginterpretasian pesan. Selain itu, emotikon juga dapat menunjukkan emosi serta kondisi sang penulis. Oleh karena itu, dapat dikatakan bahwa emotikon yang memiliki fungsi untuk mengklarifikasikan pesan tekstual, merupakan hal yang serupa dengan fungsi nonverbal dalam percakapan tatap muka (Derks, 2007).

Kaomoji yang secara harfiah memiliki arti "huruf wajah" adalah emotikon versi Jepang. Berbeda dengan emotikon buatan Amerika yang ditulis secara menyamping seperti :-) atau :$\mathrm{O}$, kaomoji memiliki bentuk yang lebih ekspresif dan ditulis secara mendatar, seperti $\left(\wedge_{-}{ }^{\wedge}\right)$ dan (-_-;), sehingga mempermudah pemahaman dalam membaca emotikon tersebut. Elemen utama yang membentuk kaomoji terdiri dari tanda kurung tutup "( )" sebagai wajah, tanda caret atau tanda minus "-" sebagai mata, dan garis bawah “"” sebagai mulut. Kaomoji tidak hanya mengekpresikan wajah dan emosi, tetapi juga memperlihatkan gerakan tubuh lainnya yang pada umumnya tidak dapat ditemukan dalam emotikon, misalnya dengan menambahkan tanda " $\backslash /$ " sebagai gerakan tangan $\backslash\left(\wedge_{-} \wedge\right) /$.

Apabila dilihat secara sekilas, kaomoji terlihat mirip dengan tokoh-tokoh kartun gaya Jepang, muka bulat dengan ekspresi muka yang identik dengan Anime. Penggunaan kaomoji dalam komunikasi non verbal ini dapat meminimalisirkan kesalahpahaman yang dapat terjadi akibat salah penafsiran akan tulisan yang dibuat oleh orang lain. Oleh karena itu, dalam penelitian ini penulis akan mengangkat topik tentang representasi dan interpretasi kaomoji melalui pendekatan semiotika pierce. 


\section{Metode Penelitian}

Metode yang digunakan adalah analisis isi kualitatif berupa semiotika Pierce. Salah satu prinsip komunikasi adalah komunikasi melibatkan tanda dan kode. Tanda adalah material atau tindakan yang menunjuk pada 'sesuatu', sementara kode adalah sistem tanda-tanda yang diorganisasikan dan menentukan bagaimana tanda dihubungkan dengan yang lain. Dengan demikian, pusat perhatian semiotika pada kajian komunikasi adalah menggali apa yang tersembunyi dibalik bahasa verbal atau nonverbal. Penelitian ini menganalisis makna simbol kaomoji bahasa Jepang.

\section{Pembahasan}

Komunikasi non verbal adalah proses komunikasi melalui pengiriman dan penerimaan pesan tanpa penggunaan kata-kata (Devito, 2002). Liliweri juga (1994:89) berpendapat bahwa komunikasi nonverbal seringkali dipergunakan untuk menggambarkan perasaan dan emosi. Jika pesan yang diterima melalui sistem verbal tidak menunjukkan kekuatan pesan, maka penerima pesan dapat menerima tanda-tanda nonverbal lainnya sebagai pendukung. Dari sini dapat dilihat bahwa pesan nonverbal berperan dalam proses pemahaman pesan verbal yang diterima. Jandt (1998:104-116) membagi komunikasi non verbal ke dalam sembilan jenis, yaitu kinesics (gerak tubuh); paralanguage (suara); visual ; haptics (sentuhan); proxemics (kedekatan); chronemics (waktu), kebisuan, olfactics (penciuman) dan oculesics (pesan yang disampaikan melalui mata). Penelitian kaomoji ini termasuk ke dalam komunikasi visual, yaitu salah satu bentuk komunikasi yang digunakan untuk menyampaikan pesan berupa gambar, grafik, lambang dan simbol.

Kaomoji (顔文字) merupakan gaya emotikon popular Jepang yang terdiri dari karakter Jepang dan tanda baca tata bahasa yang digunakan untuk mengekspresikan emosi di sms dan komunikasi dunia maya (komunikasi non verbal). Secara harfiah, dalam bahasa Jepang "kao" berarti 'wajah' dan "moji” berarti 'karakter', jadi kaomoji dapat diterjemahkan sebagai 'karakter yang dapat mencerminkan ekspresi wajah'. Dalam meikyo kakugo jiten menyebutkan bahwa kaomoji adalah "Ekspresi muka yang terbuat dari simbol dan digunakan dalam pesan elektronik, seperti $\left({ }^{\wedge} \mathrm{O}^{\wedge}\right),\left({ }_{-}-;\right)$, yang kurang lebih digunakan untuk mengungkapkan perasaan (Virginianty, 2012). Sebelumnya emotikon muncul untuk pertama kalinya di Amerika Serikat pada tahun 1980 dengan simbol :-) atau :) yang dikenal dengan istilah 'smiley'. Emoji (絵文字) pada awalnya memiliki arti pictograph, dan secara harfiah memiliki arti 'gambar dan karakter'. Emoji pada dasarnya memiliki fungsi yang sama dengan kaomoji, akan tetapi berbeda dengan kaomoji yang terbuat dari berbagai simbol penulisan, emoji memiliki standarisasi, bentuk yang pasti dan dibuat secara set. Sugimoto dan Levin (2000) mengemukakan bahwa perbedaan antara emoji dan kaomoji antara lain, 1) arah dari lambang, emoji ditulis secara vertical :-) dan kaomoji ditulis secara horizontal ${ }^{\wedge} \mathrm{O}^{\wedge}$; dan 2 ) fokus ekspresi, emoji lebih fokus ke mulut, sementara kaomoji mengemfasiskan di mata (Katsuno \& Yano, 2002).

Semiotika dapat dijelaskan sebagai ilmu mengenai tanda. Semiotika melihat tanda sebagai dua sisi uang logam yang tak terpisahkan. Di satu sisi terdapat penanda (signifier) yang dapat diasosiasikan dengan representament dalam semiotika pierce. Pada sisi lain, terdapat pertanda (signified) yang dapat diasosiasikan sebagai interpretant dalam konsep Pierce. Konsep Pierce menjelaskan terdapat relasi antara representament (hasil representasi) 
dan interpretant (hasil interpretasi) yang mengakibatkan adanya simbol, indeks, dan ikon (Sobur, 2009:42).

Dalam semiotika, konotasi, dan denotasi juga memiliki makna yang penting. Hal ini berkaitan dengan bagaimana sebuah tanda diinterpretasikan (signified). Makna denotasi dapat dikatakan sebagai makna pertama sedangkan makna konotasi dapat disebut sebagai makna kedua (Wibowo, 2011:17).

Berikut ini adalah representasi dan interpretasi dari kaomoji menggunakan semiotika Pierce.

\begin{tabular}{|c|c|c|c|c|c|c|}
\hline \multirow{3}{*}{$\begin{array}{c}\text { No } \\
\\
1 .\end{array}$} & \multirow{3}{*}{$\begin{array}{c}\text { Gambar } \\
(\geqq \forall \leqq) /\end{array}$} & \multicolumn{4}{|c|}{ Representasi } & \multirow[t]{2}{*}{ Interpretasi } \\
\hline & & Mata & Mulut & Lain-lain & Ekspresi & \\
\hline & & $\geqq \leqq$ & $\forall$ & $\begin{array}{c}\text { / } \\
\text { (tangan kiri) }\end{array}$ & Senang & $\begin{array}{l}\text { Menyatakan ekspresi } \\
\text { senang dengan mata } \\
\text { tertutup, pipi memerah, } \\
\text { mulut sedikit terbuka, } \\
\text { dan tangan kiri terangkat }\end{array}$ \\
\hline 2. & \urcorner$(?+?) \Gamma$ & $? ?$ & - & $\begin{array}{c}7 \Gamma \\
\text { (tangan) }\end{array}$ & $\begin{array}{l}\text { Bingung, } \\
\text { Bertanya- } \\
\text { tanya }\end{array}$ & $\begin{array}{l}\text { Menyatakan ekspresi } \\
\text { bingung atau bertanya- } \\
\text { tanya dengan simbol } \\
\text { mata kebingungan, mulut } \\
\text { tertutup dan tangan } \\
\text { terangkat menekuk } \\
\text { keluar }\end{array}$ \\
\hline 3. & $\left(T_{-} T^{\prime}\right)$ & $\mathrm{TT}$ & - & - & Menangis & $\begin{array}{l}\text { Menyatakan ekspresi } \\
\text { menangis dengan simbol } \\
\text { mata yang sedang } \\
\text { mengeluarkan air mata } \\
\text { dan mulut tertutup }\end{array}$ \\
\hline 4. & $(@ \sim @)$ & $@ @$ & $\sim$ & - & Pusing & $\begin{array}{l}\text { Menyatakan ekspresi } \\
\text { pusing dengan simbol } \\
\text { mata berkunang-kunang } \\
\text { dan mulut tertutup }\end{array}$ \\
\hline 5. & $(\|\nabla\|)$ & - & $\nabla$ & $\begin{array}{c}\prime \prime \prime \prime \\
\text { (pipi) }\end{array}$ & $\begin{array}{l}\text { Tersipu } \\
\text { malu }\end{array}$ & $\begin{array}{l}\text { Menyatakan ekspresi } \\
\text { bahagia dengan mulut } \\
\text { terbuka lebar dan pipi } \\
\text { memerah }\end{array}$ \\
\hline 6. & $\left({ }^{\wedge} 3^{\wedge}\right)$ & $\wedge \wedge$ & 3 & - & Cium & $\begin{array}{lr}\text { Menyatakan ekspresi } \\
\text { mencium dengan mata } \\
\text { sedang tertutup senang } \\
\text { dan mulut sedang } \\
\text { manyun }\end{array}$ \\
\hline 7. & $\backslash\left(\wedge^{\wedge} \mathrm{O}^{\wedge}\right) /$ & $\wedge \wedge$ & $\mathrm{O}$ & $\begin{array}{c}\backslash / \\
\text { (tangan) }\end{array}$ & $\begin{array}{l}\text { Memberi } \\
\text { semangat }\end{array}$ & $\begin{array}{lr}\text { Menyatakan } & \text { ekspresi } \\
\text { memberi } & \text { semangat } \\
\text { dengan mata } & \text { tertutup } \\
\text { senang, mulut terbuka } \\
\text { dan kedua } \\
\text { terangkat }\end{array}$ \\
\hline 8. & $\mathrm{~m}\left(\mathrm{u} \_\mathrm{u}\right) \mathrm{m}$ & $\mathrm{u} \mathrm{u}$ & - & $\mathrm{m} \mathrm{m}$ & Minta & Menyatakan \\
\hline
\end{tabular}




\begin{tabular}{|c|c|c|c|c|c|c|}
\hline & & & & (tangan) & $\begin{array}{l}\text { Maaf, } \\
\text { Minta } \\
\text { Tolong }\end{array}$ & $\begin{array}{l}\text { untuk meminta maaf atau } \\
\text { meminta tolong dengan } \\
\text { kepala menunduk, mulut } \\
\text { dan mata tertutup serta } \\
\text { tangan mengepal }\end{array}$ \\
\hline 9. & $(; ;)$ & $; ;$ & - & - & $\begin{array}{l}\text { Sedih } \\
\text { menitikkan } \\
\text { air mata }\end{array}$ & $\begin{array}{l}\text { Menyatakan ekspresi } \\
\text { sedih dengan simbol } \\
\text { mata yang menitikan air } \\
\text { mata dan mulut tertutup }\end{array}$ \\
\hline 10. & $(\wedge$ 人^) & $\wedge \wedge$ & - & 人 & Memohon & $\begin{array}{l}\text { Menyatakan ekspresi } \\
\text { memohon dengan mata } \\
\text { tertutup dan tangan } \\
\text { ditempelkan sebagai } \\
\text { bentuk permohonan }\end{array}$ \\
\hline 11. & $\left({ }^{\circ}\right.$ д $\left.^{\circ} ;\right)$ & $\circ$ & д & $\begin{array}{c}\text {; } \\
\text { (keringat) }\end{array}$ & $\begin{array}{c}\text { Kaget, } \\
\text { takut }\end{array}$ & $\begin{array}{l}\text { Menyatakan ekspresi } \\
\text { kaget atau takut dengan } \\
\text { mata terbuka dan mulut } \\
\text { terbuka ragu-ragu serta } \\
\text { keringat yang muncul di } \\
\text { dahi }\end{array}$ \\
\hline 12. & $(\# ` \wedge)$ & ' & $\wedge$ & $\begin{array}{c}\# \\
\text { (urat kepala) }\end{array}$ & $\begin{array}{l}\text { Marah, } \\
\text { Benci }\end{array}$ & $\begin{array}{l}\text { Menyatakan } \\
\text { marah ekspresi } \\
\text { memicingkan dengan } \\
\text { mulut sedikit terangkat } \\
\text { dan simbol "\#” yang } \\
\text { menyatakan urat kepala } \\
\text { yang berdenyit ketika } \\
\text { marah }\end{array}$ \\
\hline 13. & $(-.-) Z z z$ & -- & . & Zzz & Tidur & $\begin{array}{l}\text { Menyatakan ekspresi } \\
\text { tidur dengan mata dan } \\
\text { bibir tertutup, serta } \\
\text { simbol "Zzz" sebagai } \\
\text { bunyi orang tidur }\end{array}$ \\
\hline 14. & $\left(\neg \_\neg\right)$ & $\neg$ & - & - & Kesal & \begin{tabular}{lrr}
\multicolumn{2}{l}{ Menyatakan } & ekspresi \\
kesal dengan & mata \\
melirik & dan & mulut \\
tertutup & & \\
\end{tabular} \\
\hline 15. & $(\cdot \cdot \omega \cdot)$ & $\cdot \cdot$ & $\omega$ & $\begin{array}{l}\text { (alis) } \\
\text { (alis) }\end{array}$ & Muka tebal & $\begin{array}{l}\text { Menyatakan ekpresi } \\
\text { tebal muka dengan alis } \\
\text { terangkat, mata terbuka } \\
\text { dan mulut menyerupai } \\
\text { kucing }\end{array}$ \\
\hline 16. & $f\left(\wedge \_\wedge\right)$ & $\cdot$ & - & $\begin{array}{c}\mathrm{f} \\
\text { (tangan } \\
\text { kanan) }\end{array}$ & Malu & $\begin{array}{l}\text { Menyatakan ekspresi } \\
\text { malu dengan mata } \\
\text { tertutup senang, mulut } \\
\text { tertutup dan tangan } \\
\text { kanan menggaruk kepala }\end{array}$ \\
\hline 17. & $($;'д $’) /^{\prime}$ & 八 & Д & / (tangan & Perpisahan & Menyatakan ekpresi \\
\hline
\end{tabular}




\begin{tabular}{|c|c|c|c|c|c|c|}
\hline & & & & $\begin{array}{c}\text { kiri), } \\
; \text { (air mata) }\end{array}$ & & $\begin{array}{l}\text { perpisahan dengan mata } \\
\text { sayu mengeluarkan air } \\
\text { mata, mulut sedikit } \\
\text { terbuka, dan tangan kiri } \\
\text { melambai }\end{array}$ \\
\hline 18. & $\left(\wedge^{\wedge} v^{\circ}\right) v$ & $\wedge^{\circ}$ & $\mathrm{V}$ & - & Genit & $\begin{array}{lr}\text { Menyatakan } & \text { ekspresi } \\
\text { genit } & \text { dengan } \\
\text { mengedipkan mata } \\
\text { sebelah dan tersenyum } \\
\text { genit serta tangan } \\
\text { membuat simbol "peace" }\end{array}$ \\
\hline 19. & $(\Theta ロ \Theta)$ & $\Theta \Theta$ & 口 & - & Menguap & $\begin{array}{l}\text { Menyatakan ekspresi } \\
\text { menguap dengan mata } \\
\text { tertutup dan mulut } \\
\text { terbuka lebar }\end{array}$ \\
\hline 20. & $(\bigcirc \circ \bigcirc !) /$ & () () & $\mathrm{O}$ & $\begin{array}{l}\text { / (tangan } \\
\text { kiri) } \\
! \text { (terkejut) }\end{array}$ & Terkejut & $\begin{array}{l}\text { Menyatakan ekspresi } \\
\text { terkejut dengan mata } \\
\text { melotot, mulut terbuka } \\
\text { dan tangan kiri terangkat } \\
\text { ke pipi serta simbol "!" } \\
\text { yang terdapat di dahi } \\
\text { menyatakan keterkejutan }\end{array}$ \\
\hline
\end{tabular}

Selain kaomoji yang telah dipaparkan di atas, terdapat variasi kaomoji lainnya yang bisa dibentuk dengan menggunakan simbol-simbol kaomoji yang telah dipaparkan sebelumnya. Berikut variasi-variasi kaomoji yang bisa dibentuk dari simbol-simbol sebelumnya.

\begin{tabular}{|c|c|c|c|c|c|c|c|c|c|c|}
\hline & $\forall$ & - & $\omega$ & 3 & $\mathrm{~V}$ & $\mathrm{O}$ & $\sim$ & д & $\wedge$ & 口 \\
\hline$\geqq \leqq$ & $(\geqq \forall \leqq)$ & $\left(\geqq \_\leqq\right)$ & $(\geqq \omega \leqq)$ & $(\geqq 3 \leqq)$ & $(\geqq \mathrm{v} \leqq)$ & $(\geqq 0 \leqq)$ & $(\geqq \sim \leqq)$ & $(\geqq д \leqq)$ & $(\geqq \wedge \leqq)$ & $(\geqq ロ \leqq)$ \\
\hline$\circ \quad$ & $\left({ }^{\circ} \forall^{\circ}\right)$ & $\left({ }^{\circ}{ }^{\circ}\right)$ & $\left({ }^{\circ} \omega^{\circ}\right)$ & $\left({ }^{\circ} 3^{\circ}\right)$ & $\left(\mathrm{r}^{\circ}{ }^{\circ}\right)$ & $\left({ }^{\circ} \mathrm{O}^{\circ}\right)$ & $\left({ }^{\circ} \sim{ }^{\circ}\right)$ & $\left({ }^{\circ}\right.$ д $\left.^{\circ}\right)$ & $\left({ }^{\circ} \wedge{ }^{\circ}\right)$ & $\left({ }^{\circ}\right.$ 口 $\left.^{\circ}\right)$ \\
\hline$\wedge \hat{n}$ & $\left(\wedge^{\wedge} \forall^{\wedge}\right)$ & $(\hat{\imath})$ & $\left(\hat{\omega} \omega^{\wedge}\right)$ & $\left(\wedge 3^{\wedge}\right)$ & (^v) & $(\hat{\mathrm{O}})$ & $(\wedge \sim \wedge)$ & (^д) & $\left(\wedge^{\wedge}\right)$ & (^ロ^) \\
\hline$\wedge^{\circ}$ & $\left(\wedge \forall^{\circ}\right)$ & $\left(\wedge_{-}^{\circ}\right)$ & $\left(\wedge^{\wedge} \omega^{\circ}\right)$ & $\left(\wedge 3^{\circ}\right)$ & $\left(\wedge v^{\circ}\right)$ & $\left(\wedge^{\circ}{ }^{\circ}\right)$ & $(\wedge \sim 0)$ & $\left(\wedge^{\wedge}{ }^{\circ}\right)$ & $\left(\wedge \wedge^{\circ}\right)$ & (^ロロ $)$ \\
\hline$x^{\prime}$ & $\left({ }^{\prime} \forall^{\prime}\right)$ & ('_) & $\left({ }^{\prime} \omega^{\prime}\right)$ & (‘3) & ('v') & (`o') & $(` \sim)$ & (`д') & (`^) & (`ロ) \\
\hline 、 & $\left(\forall^{\prime}\right)$ & $\left({ }_{-}^{\prime}\right)$ & $\left(\omega^{\prime}\right)$ & $\left(3^{\prime}\right)$ & $\left({ }^{\prime} v^{\prime}\right)$ & (’o`) & $\left(\prime^{\prime} \sim\right)$ & ('д’) & $\left({ }^{\prime \prime}\right)$ & (’ロ`) \\
\hline-- & $(-\forall-)$ & $\left(-_{-}^{-}\right)$ & $(-\omega-)$ & $(-3-)$ & $(-\mathrm{v}-)$ & $(-0-)$ & $(-\sim-)$ & (-д-) & $(-\wedge-)$ & (-ロ-) \\
\hline$\neg \neg$ & $(\neg \forall \neg)$ & $\left(\neg \_\neg\right)$ & $(\neg \omega \neg)$ & $(\neg 3 \neg)$ & $(\neg \mathrm{v} \neg)$ & $(\neg \mathrm{O} \neg)$ & $(\neg \sim \neg)$ & $(\neg д \neg)$ & $(\neg \wedge \neg)$ & (フロフ \\
\hline$\prime \prime \prime \prime$ & $(\|\forall\|)$ & $(" I \prime \prime)$ & $(\| \omega \prime \prime)$ & $(" / 3 \|)$ & $($ (IV $\mathrm{v} /)$ & $(" \prime \mathrm{O} / \prime)$ & $(I \prime \sim \prime \prime)$ & ( " д " & $(\|\wedge\|)$ & ( " ロ " $)$ \\
\hline$\Theta \Theta$ & $(\Theta \forall \Theta)$ & $\left(\Theta \_\Theta\right)$ & $(\Theta \omega \Theta)$ & $(\Theta 3 \Theta)$ & $(\Theta \mathrm{v} \Theta)$ & $(\Theta \circ \Theta)$ & $(\Theta \sim \Theta)$ & $(\Theta д \Theta)$ & $(\Theta \wedge \Theta)$ & $(\Theta 口 \Theta)$ \\
\hline () (-) & (@ $\forall$ (○) & (@_@) & $(\bigcirc \omega \bigcirc)$ & (@3@) & (@v@) & (@o@) & (@〜 @) & (@д@) & (@^@) & (○口(○) \\
\hline$@ @$ & $(@ \forall @)$ & $\left(@ \_@\right)$ & $(@ \omega @)$ & (@3@) & $(@ \mathrm{v} @)$ & $\left(@_{0} @\right)$ & $(@ \sim @)$ & $(@$ д@) & (@へ@) & (@口@) \\
\hline $\mathrm{T} \mathrm{T}$ & $(\mathrm{T} \forall \mathrm{T})$ & $\left(T_{-} T^{\prime}\right)$ & $(T \omega T)$ & (T3T) & (TvT) & (ToT) & $(T \sim T)$ & (ТдТ) & $(\mathrm{T} \wedge \mathrm{T})$ & (TロT) \\
\hline ; ; & $(; \forall ;)$ & $(; ; ;)$ & $(; \omega ;)$ & $(; 3 ;)$ & $(; \mathrm{v} ;)$ & $(; 0 ;)$ & $(; \sim ;)$ & $(;$; $)$ & $(; \wedge ;)$ & $(;$; ; ) \\
\hline
\end{tabular}

\section{Simpulan dan Saran}

Berdasarkan hasil penelitian di atas, dapat disimpulkan bahwa kaomoji dapat disebut sebagai alat komunikasi pengganti dalam bentuk non verbal di dalam dunia maya. Kaomoji juga membantu pengirim pesan dalam meyampaikan dan mengekspresikan perasaannya sehingga penerima pesan (pembaca) dapat memahami dengan baik maksud atau makna sesungguhnya yang ingin disampaikan oleh pengirim pesan. Untuk membuat sebuah kaomoji, elemen- 
elemen wajah yang harus ditampilkan adalah mata dan mulut yang erdapat dalam simbol tanda kurang "( )". Berapapun simbol yang digunakan, asalkan masih terdapat dalam tanda kurung maka disebut sebagai kaomoji.

\section{Daftar Pustaka}

Baldwin, John R, Perry, S.d \& Moffit, M.A. 2004. Communication Theories For Everyday Life. Boston: Pearson Education INC.

Derks, Daantje. 2007. Exploring The Missing Wink: Emotikons In Cyberspace. Leiderdrop: Copyshop.

Jandt, Fred E. 1998. Intercultural Communication An Introductions. Thousand Oaks: Sage Publications.

Katsuno, Hirofumi dan Yano, Christine R. 2002. Face to Face.: "Online Subjectivity in Contemporary Japan.” Asian Studies Review 26:205-232.

Liliweri, Alo. 1994. Komunikasi Verbal dan Non Verbal. Bandung: PT Citra Aditya Bakti.

Sendjaja, Djuarsa. 1994. Teori Komunikasi. Jakarta: Universitas Terbuka.

Sobur, Alex. 2009. Semiotika Komunikasi. Bandung: Remaja Karya Rosdakarya.

Virginianty, Gina Aghnia. 2012. Kaomoji Pada Pesan Verbal Dalam Komunikasi Media Komputer. Skripsi. FIB Universitas Indonesia.

Wibowo, Indiwan Seto Wahyu. 2011. Semiotika Komunikasi. Jakarta: Mitra Wacana Media.

Sumber Online:

http://kaomojiya.com/, di akses pada tanggal 16 April 2017

http://kaomoji.ru/en/, di akses pada tanggal 16 April 2017 